\title{
A Study On The Preferences In Personal Vehicle Mode Transformation Based On Trip Characteristics
}

\author{
NUR KHAERAT NUR
}

\author{
Alumnus of generation 93,Moslem University of Indonesia, Civil Engineering Department \\ Lecturer, Fajar University, Civil Engineering Department, Makassar, Indonesian \\ Email address: enkha93@gmail.com
}

\begin{abstract}
This study is a preference study to explore the perception of transformation of personal vehicle users (four wheelers and two wheels) based on trip characteristics. The design approach of the analysis consisted of descriptive statistical methods to obtain the characteristics of commuting personal transport in terms of travel costs, vehicle operating costs, mileage and travel time, as well as modeling SEM Partial Least Square (PLS) to get the effect of the characteristics of commuting personal transport towards the transformation of the mode of transport. Data analysis known that the trip characteristics in terms of the allocation of transport costs most respondents spends a month in the range of costs between IDR. 500,000 to IDR. $1,000,000$ per month in this case the vehicle operating costs amounted to $85.3 \%$, followed by travel expenses by $83.0 \%$.

Based on the results of hypothesis testing found that the trip characteristics significant direct effect on the endogenous variables Transformation of 5.695.
\end{abstract}

Keywords: transformation, personal vehicle mode, commuter, trip characteristics

\section{INTRODUCTION}

Transportation problems in big cities like the City of Jakarta, Bandung, Surabaya, Medan and Makassar, is an issue that is quite alarming, especially in solving the problems of public transport connection with traffic congestion. Comparing to major cities in developed countries, it is became an irony that the public transport service system in our country is very underdeveloped and quite alarming. In developed countries people are more likely to use public transport (public transport ) as compared with the use of personal vehicles. However, in big cities such as Makassar, in general, people prefer to use personal vehicles compared to public transportation with various comments and reasons such as discomfort, longer travel time, the capacity of public transport is not operated as it should be so that security cannot be obtained and many other reasons. Aspects of the population, information technology, and values contained in those countries are different to the countries with cities in developing countries such as Indonesia. Therefore, this study specifically conducted on personal transportation were compared to previous studies, both in the types of modes, as well as the level of service provision, even more priority to the supply side ( supply) rather than the demand side.

Makassar City with an area of $175.77 \mathrm{~km} 2$ as the core city Mamminasata Metropolitan Region and serves as the National Events Centre in Eastern Indonesia with a population of approximately 1.5 million people experienced a growth rate of $9 \%$ per year. Economic indicators town with the GDP dominated by trade and services.Therefore , the Makassar city owns a very high tourism charm, but it faces a variety of urban problems, namely urbanization and poverty, slums, transport, flood, water, sanitation, and solid waste. At an inter-city 
movement, modes choice factor plays a fairly important, someone who would move from one city to another would have to consider a lot of things, namely whether the movement is doing.

Transport problems encountered include: (1) an imbalance in the development of road infrastructure in comparison with the growth of the vehicle, (2) the growth of road infrastructure of approximately $4 \%$ per year, and (3) the growth of the vehicle approximately $14-15 \%$ per year. A survey conducted by ARSDS concluded that the ratio of use of personal vehicles and public transport is $611: 35$. This clearly shows the inefficiency of the use of road space by the pattern of use of the vehicle. The growth of the use of vehicles in Makassar indicate a trend the utilization of motor vehicles and the disappearance of non-motorized vehicles. This will cause the pressure on the environment both energy use and the environmental pollution. A policy adopted by the Government, in addition to building a supporting infrastructure for such an attempt restrictions on personal transportation, with the expectation of traveling by public transportation.

Thus, the practical is to encourage personal vehicle users to change into public transport users. However, Makassar is experiencing economic growth and rapid population growth. The impact of rapid economic growth increase public revenues, which tends to encourage people to own and drive a personal vehicle. The fundamental purpose of public transport is organizing good and decent services for the community (Warpani, 1990).

Improved quality of transport infrastructure and the lack of good tools and services to public transport are also increasingly encouraging people to own and drive a personal vehicle. These things will be an obstacle to efforts the "socialize " for the use of public transportation . In addition to the economic capability of a person and the availability of public transportation are sufficient in number, presumably other environmental factors affect a person's tendency to choose the mode of transport.

\section{REVIEW OF LITERATURE}

Transport in general (Department of Transportation, 1997) can be defined as the activities of the movement of goods and people from the place of origin to the destination which forms a relationship that consists of three parts: there are cargo to be shipped, availability of the facility as a means of conveyance, and availability of the infrastructure of road. Transportation process is the movement of the transport start from the place of origin to destination where the transport activities are terminated.

Transportation is done because the value from people or goods transported will be higher in another place (destination) than at the place of origin (Morlok, 1995). In Weber 's Locational Theory of Minimum Cost, an economist Alfred Weber Germany states that the location of any industry depends on the total cost of the transportation and labor where the sum of the two should be the minimum. The waiting time is the time taken by the passengers to wait for public transport in the halt. In general, the passengers need a relatively short time (Sonny Siswandi MK, 2009). With the increasing mobility of people and goods in turn, people will demand transportation services with a higher level of safety, security, speed, smoothness and comfort (Paul Raga, 2004). Service performance indicator is an appropriate concept form which is a measure or means to reach the goal, concerning aspects of economic and technical or operation of the system performance. The performance indicators are the right size in the form of single data or comparison of two or more of a data. (Giannopoulos, G.A, 1989).

The former research in the field of transport that relevant to this study are: Lakawa, et al (2016) who modelling the interaction of traffic characteristics, physical aspects of the road, road environment, and the implications to traffic noise level. Kai Chieh HU (2011) examines about "Effects of Service Guarantee and Perceived Waiting Experience on Railway Passenger's 
Repurchase Intentions", stating that in rail transport, passengers have to wait for a delayed schedule. The evaluation obtained from the passengers' experience that waits can cause negative things like emotions and degrade the service. Vu Anh Tuan (2011) in his research on "Dynamic Interactions between Personal Passenger Car and Motorcycle Ownership in Asia: A Cross-country Analysis", stating that Motorization in Asia is characterized by the rapid growth of motorcycles and cars in the possession and their interactions from time to time.

\section{RESEARCH METHODS}

\subsection{Research design}

The method used is descriptive analysis, which depicts an event then performs an analysis of the problems that arise. Design or research design is a detailed planning used as a guide of the research studies that lead to the goal of the study, Aaker et al. (2001: 24). The study began by collecting literature and secondary data relating to the research conducted then determine the used survey technique. In this study the events that will be observed is the selection of personal transport modes. The variables studied are the attributes characteristic of the trip. The data collection technique is by interviews or questionnaires to users of personal vehicles on the work ( employees ) with a random system . Question survey form consists of two things; the first one is questions are focused on determining the existing condition of the current characteristics of personal vehicle users. In this case we want to know the travel information is done using personal transport modes. Questions directed to know the preferences of respondents who have offered hypothetical conditions such as the allocation of travel costs, vehicle operating costs, travel time and mileage. Using data from the perception of respondents are then analyzed to determine the characteristics of commuters traveling on personal transport modes in Makassar.

This research was developed based modes of commuter transportation issues with an emphasis on commuter characteristic effects on the transformation of the mode of transport commuters using Structural Equation Modeling (SEM) with Partial Least Square (PLS). The implementation of Structural Equation Model (SEM) in actual study was actually to compare or show the difference between the sample covariance (data) with covariance predicted by the model, the difference obtained was also called as residual (Wijanto, 2008).

The research was conducted in the city of Makassar, particularly the use of personal vehicles which civil servants (PNS) working in the Office of the Governor of South Sulawesi Province, conducted in-person to the respondents, especially when questionnaires. Research was conducted on every working day.

\subsection{Data analysis technique}

Methods of data analysis used in this study are generally divided into three, namely:

1. Descriptive Statistics Methods

This method is used to determine the trip characteristics of personal transport in the form of tables and diagrams, so it is easy to understand. The data used in this method is sourced on a questionnaire distributed to a sample transport users of personal cars and motorcycles with employee respondents office of Governor of South Sulawesi Province. The method of sampling using Simple Random Sampling.

2. Descriptive Qualitative Methods

This method is used to determine the perception of personal transformation of modes of transport users is based on the characteristics of the respondent employees commuting to the office of Governor of South Sulawesi province. 
3. Method Structural Equation Modeling With Partial Least Square

This method is used to analyze the influence of the characteristics of personal commuter transport users to the transformation modes.

\section{ANALYSIS AND DISCUSSION}

\subsection{Analysis Characteristics of Travel Commuter and Transformation Mode of Transport}

1. Characteristics of Latent Variable Allocation of Transportation Costs (X1)

Respondents' perceptions of the allocation of transportation costs within a month from the home place of work which is manifested in travel expenses by <IDR. 500,000 are in the range of $39.5 \%$, 500,000 - about 43.5\% IDR.1.000.000, IDR.1.000.000 IDR.1.500.000 approximately 15.4\% IDR.1.500.000 - IDR.2.000.000 in the range of $1.6 \%$ while for the travel costs of <IDR. 2,000,000 there are respondents who chose the $0 \%$.

Indicators of cost allocation of transport costs in terms of vehicle operating costs amounted month <IDR. 500,000 are in the range of 36.3\%, 500,000 - about $49.0 \%$ IDR.1.000.000, IDR.1.000.000 - IDR.1.500.000 approximately 8.5\% IDR.1.500.000 IDR.2.000.000 in the range of $0.7 \%$, and for travel expenses amounted to > IDR. $2,000,000$ in the range of $5.6 \%$.

Table 1. Characteristics of latent variable allocation of transportation costs (X1) and the indicator variables, the cost of travel (X11) and Operating costs of vehicles Mileage (X12)

\begin{tabular}{lllllll}
\hline No. Indicator variable & \multicolumn{5}{c}{ Distribution of respondents (\%) } \\
\cline { 3 - 6 } & & 1 & 2 & 3 & 4 & 5 \\
\hline 1 & Allocation of Transportation Costs (X1) & & & & & \\
& - The cost of travel (X11) & 39.5 & 43.5 & 15.4 & 1.6 & 0.0 \\
& - Operating costs of vehicles Mileage (X12) & 36.3 & 49.0 & 8.5 & 0.7 & 5.6 \\
\hline
\end{tabular}

Data Sources: Primary Data Processing

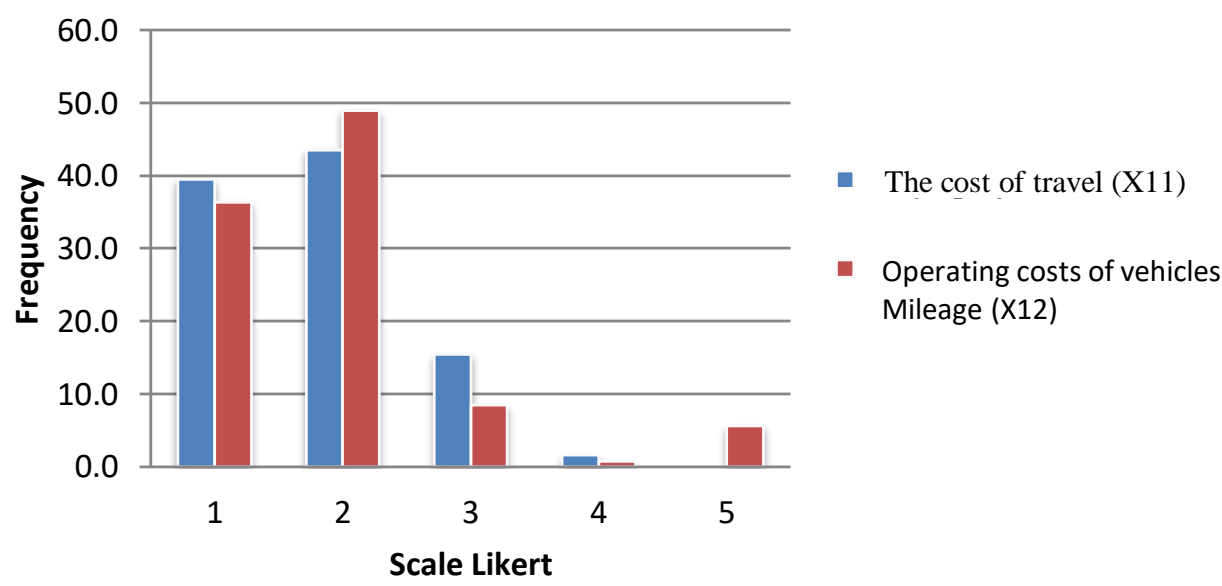

Figure 1. Distribution Frequency response of Latent Variable allocation of transportation costs (X1) and the indicator variables (X11and X12) 
2. Characteristics of Latent Variable mileage and travel time (X2)

Respondents' perceptions of mileage and travel time from home to the place of work which is manifested in the mileage along the $0-5 \mathrm{~km}$ in the range of $3.3 \%, 5-10 \mathrm{~km}$ around $22.9 \%, 10-15 \mathrm{~km}$ around $43.5 \%, 15-20 \mathrm{~km}$ around $21.9 \%$ and for mileage $>20 \mathrm{in}$ the range of $8.5 \%$. For indicators in terms of travel time for $<30$ minutes in the range of $20.9 \%, 30$ minutes - 1 hour around 55.6\%, $1-1.5$ hours approximately 8.2\%, $1.5-2$ hours $12.1 \%$. and for travel expenses by> 2 hours in the range of $3.3 \%$.

Table 2. Characteristics of the variable mileage and travel time (X2) and an indicator variable Milege X21 and Travel Time (X22)

\begin{tabular}{llccccc}
\hline No. & Indicator variable & \multicolumn{5}{c}{ Distribution of Respondents (\%) } \\
\cline { 3 - 7 } & & $\mathbf{1}$ & $\mathbf{2}$ & $\mathbf{3}$ & $\mathbf{4}$ & $\mathbf{5}$ \\
\hline $\mathbf{1}$ & The mileage and travel time (X2) & & & & & \\
- & Mileage (X21) & 3.3 & 22.9 & 43.5 & 21.9 & 8.5 \\
- & Travel time (X22) & 20.9 & 55.6 & 8.2 & 12.1 & 3.3
\end{tabular}

Data Sources: Primary Data Processing

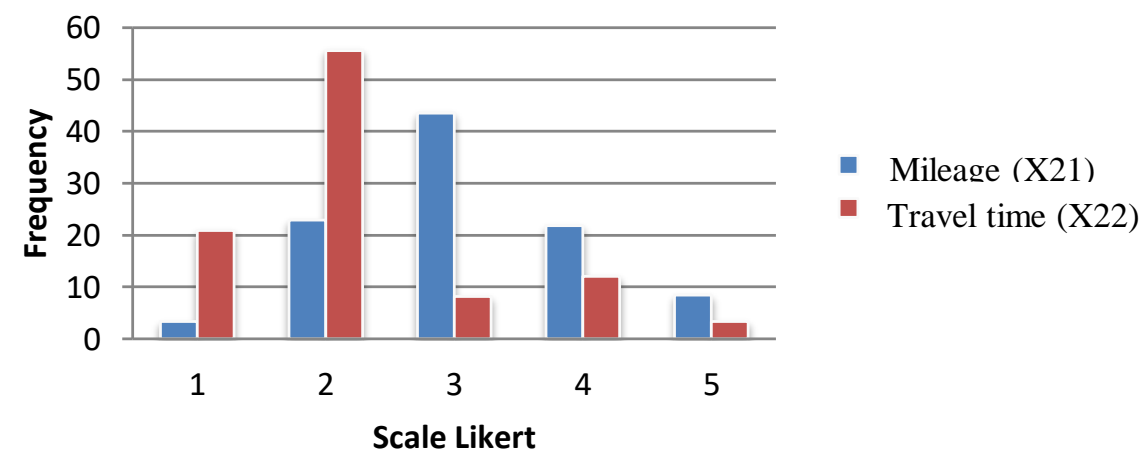

Figure 2. Distribution Frequency response of Latent Variable mileage (X21) and travel time (X22)

3. Characteristics of Variable Transformation Mode (Y)

Respondents' perceptions of the transformation of mode of travel that is manifested by an indicator variable in terms of willingness to move using public transport modes respondents stated strongly agree amounted to $18.3 \%$, agreed amounted to $20.6 \%$, less agreed at $22.2 \%$, disagreed by $28.1 \%$ and stating very agreed amounted to $10.8 \%$.

Indicators in terms of factors main priorities that affect willing to move to public transport, people who said factor travel time amounted to $38.2 \%$, a factor timeout by $16.7 \%$, total factor tariff traveling by $12.7 \%$ safety factor of $9.8 \%$, the safety factor of $7.8 \%$, the convenience factor of $6.5 \%$, the mode of transfer factor of $4.2 \%, 3.6 \%$ access time factor and the states cultural factors (image) by $0.3 \%$. 
Table 3. Characteristics of Latent Variable Transformation Mode (Y) and Variable Indicator Willingness to move to public transport (Y1) and The main priority factor switch to public transport (Y2)

No. Indicator variable

\section{Distribusi Responden $(\%)$}

$\begin{array}{lllllllll}1 & 2 & 3 & 4 & 5 & 6 & 7 & 8 & 9\end{array}$

1 Transformation Modes of transport

$\begin{array}{llllll}\text { - Willingness to move to public } & 10.8 & 28.1 & 22.2 & 20.6 & 18.3\end{array}$ transport (Y1)

- The main priority factor switch to public transport (Y2)

$\begin{array}{lllllllll}16.7 & 38.2 & 3.6 & 4.2 & 12.7 & 6.5 & 9.8 & 7.8 & 0.3\end{array}$

Data Sources: Primary Data Processing

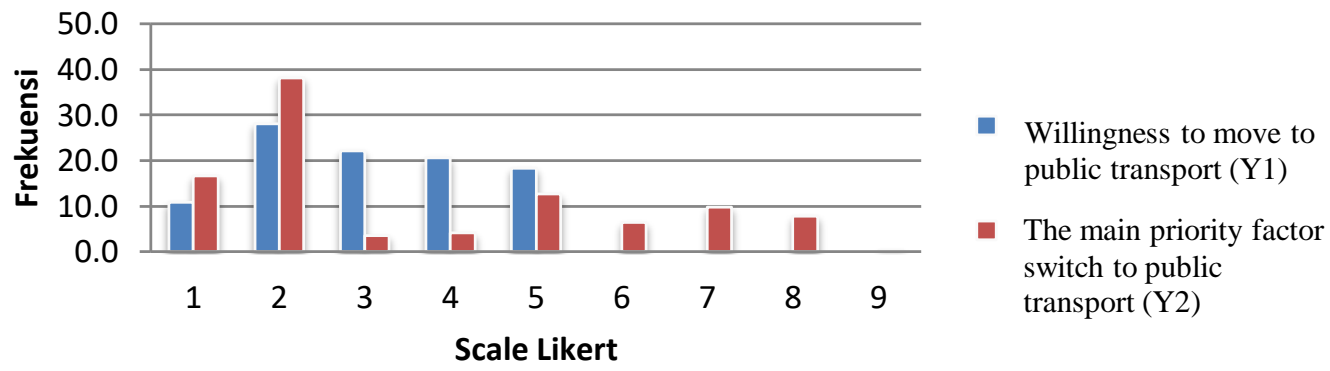

Figure 3. Distribution Frequency response of Latent Variable Transformation Mode (Y) and the indicator ( Y1 and Y2)

\subsection{Commuter Travel Characteristics Effect of Transformation Mode}

\subsubsection{Conceptual Model}

The design of the predictive relationship path (Path Diagram) illustrating the effect of exogenous construct the endogenous constructs. While the outer models describing the relationship between variables manifest the latent variables as shown in figure 4 on this page.

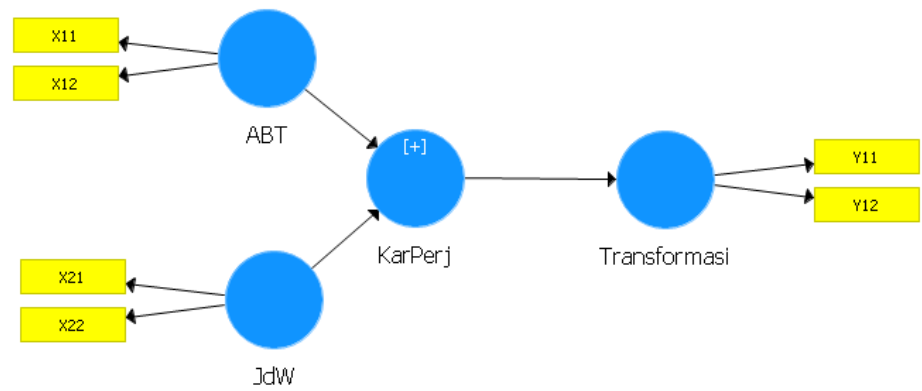

Figure 4. Diagram Full Path Model

Information :

- Trip Characteristics (KarPerj) 
- Allocation of Cost of Transportation (ABT)

- Mileage and Time (JDW)

- Transformation (Transformasi)

\subsubsection{Evaluation (Goodness of Fit)}

1) Outer Model

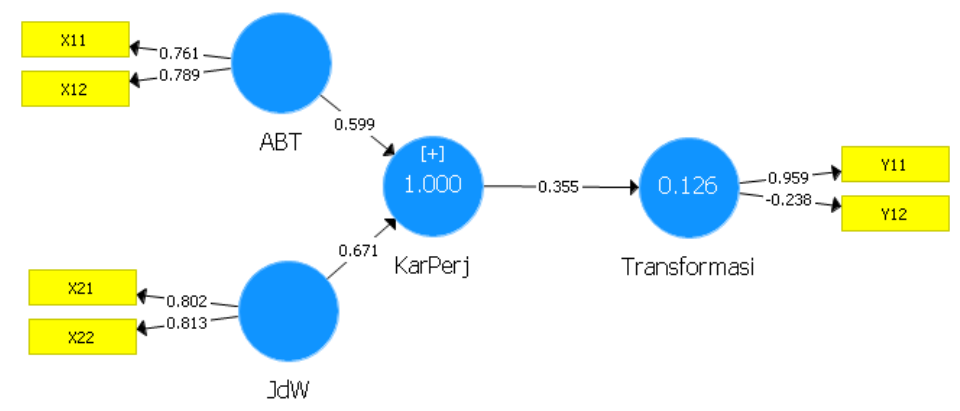

Figure 5. Output Outer Dropped Model Algorithm

In Figure 5 ,Visible value most indicators loading factor model execution results already above 0,50 (meeting the criteria of convergent validity).

In Table 5 shows that the correlation value of the indicator variable is greater than the correlation value against other constructs. These results indicate good discriminant validity.

Table 4. Values Cross Loading Validity Diskriminan

\begin{tabular}{lllll}
\hline & ABT & JdW & KarPerj & Transformation \\
\hline X11 & 0.755 & 0.166 & 0.554 & 0.222 \\
X11 & 0.755 & 0.166 & 0.554 & 0.222 \\
X12 & 0.794 & 0.201 & 0.598 & 0.203 \\
X12 & 0.794 & 0.201 & 0.598 & 0.203 \\
X21 & 0.179 & 0.797 & 0.650 & 0.181 \\
X21 & 0.179 & 0.797 & 0.650 & 0.181 \\
X22 & 0.204 & 0.818 & 0.682 & 0.232 \\
X22 & 0.204 & 0.818 & 0.682 & 0.232 \\
Y11 & 0.274 & 0.257 & 0.336 & 1.000
\end{tabular}

Data Sources: Primary Data Processing

In the table 5. Latent variable correlation, discriminant construct validity for all the variables that KarPerj, ABT, JDW, and the transformation has been met, because it has the root of average variance extracted (AVE) of 1.0 is greater than the value on the bottom. 
Table 5. Table Latent variable correlation

\begin{tabular}{lcccl}
\hline & ABT & JdW & KarPerj & Transformation \\
\hline ABT & 1.000 & & & \\
JdW & 0.237 & 1.000 & & \\
KarPerj & 0.744 & 0.826 & 1.000 & \\
Transformation & 0.274 & 0.257 & 0.336 & 1.000 \\
\hline
\end{tabular}

Data Sources: Primary Data Processing

Reliability block indicator that measures the construct seen from the composite reliability. Composite reliability will show a good value when above 0.70 .

Table 6. The reliability Test Results

\begin{tabular}{lc}
\hline & Composite Reliability \\
\hline ABT & 0.750 \\
JdW & 0.789 \\
KarPerj & 0.716 \\
Transformation & 1.000 \\
\hline \multicolumn{2}{l}{ Data Sources: Primary Data Processing. }
\end{tabular}

2) Inner Model

Evaluation of structural models (inner model) is done by looking at the value of Rsquare, Q-quare and T-test.

Table 7. Value Coefficient of Determination

\begin{tabular}{cc}
\hline Variabel & R Square \\
\hline KarPerj & 1.000 \\
Transformation & 0.113 \\
\hline Data Sources: Primary Data Processing.
\end{tabular}

Based on Table 7, Rated R-square variable trip characteristic (KarPerj) of 1,000, meaning simultaneously can be explained by the variable trip characteristics commuting (KPK) with all two variable factors in the model, namely, Cost Allocation Transportation (ABT), mileage and travel time (JDW). Then for the Transformation of variables (Transformasi) of 0.113 .

So thus amounted to $0.0 \%$ for KarPerj and $99.88 \%$ for Transformation explained by other factors not examined in this model. From the analysis of the Commission $\mathrm{Q}^{2}$ value of 1.0, and to Transformasi at 0:11. This suggests that the resulting models have predicted level was good and quite good. $\mathrm{Q}^{2}$ stretches where the value of $0 \mathrm{~s} / \mathrm{d} 1$. The closer to 1 means that the better predictive relevance.

\subsubsection{Hypothesis Testing}

Hypothesis testing is done by bootstrapping resampling method that is based on the significance of the path coefficients of the structural model. The confidence level used in this study was $95 \%$, so the level of signifkansi $(\alpha)=5 \%$ or 0.05 with t-table value 1.96 .

Table 8. Test Results Hypothesis

\begin{tabular}{lccr}
\hline Hypothesis & T tatistics & P Values & Description \\
\hline KarPerj -> Transformation & 5.695 & 0.000 & H1 diterima \\
\hline
\end{tabular}

Data Sources: Primary Data Processing 
According to Table 8. seen that the hypothesis has a t-count value is greater than t-table (1.96) that is the trip characteristic (KarPerj) to Transformation amounted to 5.695 This means that these hypotheses are significant direct effect on endogenous variable in question.

\subsubsection{Discussion of Results}

Rahmatang research results (2009), travel costs, travel time, the scheduled departure time and service levels affect the traveling public in selecting modes. Relative travel costs can be expressed as the ratio of the cost required to travel between one mode to the other modes. Ortuzar (1994) stated that in the transport cost elements that need related to the problem of mileage, time, and amount of money. (ABT), Mileage and Time (JDW) to Transformation endogeneous variable (Transformasi) seem significant influence. This is consistent with the theory according Morlok (1995), The trip characteristics of effect the traveling public in determining the choice of modes that will be used. The length of a trip to have an influence on the traveling public in the selection mode. These sizes can be obtained by measuring the mileage of the most commonly used between two central zones, both for personal vehicles or public transport. Length Other travel is the travel time from door to door. This size is often chosen in measuring the mileage as it can incorporate excess travel time on a trip.

\section{CONCLUSION}

Based on the results of research and data analysis in the discussion, it can be concluded as follows:

1. The trip characteristics in terms of the allocation of transport costs most respondents spend a month in the range of costs between IDR. 500,000 to IDR. 1,000,000 per month in this case the vehicle operating costs amounted to $85.3 \%$, followed by travel expenses by $83.0 \%$. The trip characteristics in terms of mileage and travel time, mostly along a mileage of $10-15 \mathrm{~km}$, amounting to $43.5 \%$ using the average travel time from 30 minutes up to 1 hour, amounting to $55.6 \%$. Perception of respondents to transform modes in manifested by the indicator variables in terms of willingness to move using public transport modes respondents stated strongly agree amounted to $18.3 \%$, agreed amounted to $20.6 \%$, less agreed at $22.2 \%$, disagreed by $28.1 \%$ and stating very amounted to $10.8 \%$ disagree. Indicators in terms of factors main priorities that affect willing to move to public transport, people who said factor travel time amounted to $38.2 \%$, a factor timeout by $16.7 \%$, total factor tariff traveling by $12.7 \%$ safety factor of $9.8 \%$, the safety factor of $7.8 \%$, the convenience factor of $6.5 \%$, the mode of transfer factor of $4.2 \%, 3.6 \%$ access time factor and the states cultural factors (image) by $0.3 \%$.

2. Based on the results of hypothesis testing found that the trip characteristics (KarPerj) significant direct effect on the endogenous variables Transformation (Transformasi) of 5.695 .

\section{ACKNOWLEDGMENTS}

On this occasion, we thank you and highest appreciation for the assistance and guidance to the Rector of the Fajar University and staff, two loving parents who are always sending prayers and 
encouragement, the whole family as well as civil engineering students Fajar University who helped in the data survey.

We look forward to feedback and constructive criticism for the sake of the development of this paper. Hopefully this article can be useful, especially for our personal and the public at large.

\section{REFERENCE}

Aaker, A., Kumar, V and Day, GS 2001, Marketing Research, New York: John Wiley \& Sons.

Alfred Weber, 1909. Uberden Der Standort Industrien, http://habibgeo.blogspot.co.id/2012/11/teori-lokasi-biaya-minimumweber_1473.html.

Department of Transportation Makassar, 1997. Total Municipal Transport in Makassar Region in Accordance to the Route, the Minister of Transportation Makassar.

Giannopoulos, G.A., (1989), In Vehicle Informatics applications in Road Freight Transport, paper presented at the "Mobile working" workshop, proceedings ESPRIT conference, Brussels, November 1989.

Kai Chieh HU 2011, Effects of Service Guarantee and Perceived Waiting Experience on Railway Passenger's Repurchase Intentions, Journal of the Eastern Asia Society for Transportation Studies, Vol.9.

Lakawa, I., Samang, L., Selintung, M., Hustim, M. (2016). Noise Level Study Based On Traffic Characteristics, Physical, and Environmental Aspects of Road. International Journal of Civil Engineering and Technology (IJCIET), Vol. 7 (1), pp; 188-198.

Morlok, K, Edward, 1995. Introduction to Engineering and Transport Planning. Publisher, Jakarta.

M.K. Siswandi, Sonny. 2009. "Thesis: Optimization of DAMRI City Bus Performance, Raja Basa-Tanjung Karang Bandar Lampung" Semarang Route: Not published.

Raga, Paul, MT. 2004, Assessment of Transportation Performance Services, (Warta Penelitian Perhubungan No.01/THN. XVI/2004, Jakarta, unpublished).

Warpani, (1990). Planning of Transportation Systems, Publisher ITB, Bandung.

Wijanto, 2008. Structural Equation Modeling with Lisrel 8.8 Concepts and Tutorials, Graha Ilmu.

Vu Anh Tuan, 2011. Dynamic Interactions between Personal Passenger Car and Motorcycle Ownership in Asia: A Cross-country Analysis, Journal of the Eastern Asia Society for Transportation Studies, Vol.9, 2011 